\title{
Clinical Outcome of Coronary Stenting in Patients with Variant Angina Refractory to Medical Treatment: A Consecutive Single-Center Analysis
}

\author{
Guang Chu Guobing Zhang Zhi Zhang Shaowen Liu Qinzhu Wen \\ Baogui Sun \\ Department of Cardiovascular Medicine, First People's Hospital, Shanghai Jiaotong University, Shanghai, PR China
}

\author{
Key Words \\ Variant angina $\cdot$ Coronary artery disease $\cdot$ Coronary \\ angiography · Electrocardiography · Stenting · \\ Ultrasonography · Angioplasty · Acetylcholine $\cdot$ Ischemia $\cdot$ \\ Acute coronary syndrome
}

\begin{abstract}
Objective: To investigate the efficacy of coronary stenting in patients with variant angina refractory to medical treatment. Subjects and Methods: Variant angina was diagnosed in 81 patients admitted to the Department of Cardiology between January 2003 and June 2011. However, coronary stenting was performed in 21 patients refractory to medical treatment, but coronary angiography and intravascular ultrasound were performed in all patients, and acetylcholine provocative test was performed in 11 of the 21 patients refractory to medical treatment. Coronary angiography was repeated after 9-12 months in the 21 patients with coronary stents. Clinical follow-up time was $2.5 \pm 3.1$ years (range 1-8). Results: Of the 81 patients, coronary angiography and intravascular ultrasound did not reveal significant stenosis in 13 (16.0\%), but revealed $20-75 \%$ fixed stenosis in the remaining $68(84.0 \%)$ patients. The acetylcholine provocative test was positive in the 11 patients. Of the 21 patients with coronary
\end{abstract}

\begin{tabular}{ll}
\hline KARGER & $\begin{array}{l}\text { C } 2013 \text { S. Karger AG, Basel } \\
\text { 1011-7571/13/0226-0583 } \$ 38.00 / 0 \quad \text { Karger }\end{array}$ \\
E-Mail karger@karger.com & This is an Open Access article licensed under the terms of the \\
www.karger.com/mpp & $\begin{array}{l}\text { Creative Commons Attribution-NonCommercial 3.0 Un- } \\
\text { ported license (CC BY-NC) (www.karger.com/OA-license), } \\
\text { applicable to the online version of the article only. Distribu- } \\
\text { tion permitted for non-commercial purposes only. }\end{array}$
\end{tabular}

stents, the spasm site was located in the right coronary artery in $16(76.2 \%)$ and in the left anterior descending artery in the remaining 5 (23.8\%) patients. During the 1- to 8-year followup period, 1 of the 21 patients with stents developed recurrent episodes of variant angina, 5 patients had occasional chest pain, and the other 15 were asymptomatic. Coronary angiography at 9-12 months after initial evaluation demonstrated no stenosis in 3 patients, $20-40 \%$ in-stent mild intimal hyperplasia in 15 patients, and $50-80 \%$ in-stent restenosis in 3 patients. Coronary stenting was performed again in 2 patients. Conclusions: The present study showed that coronary stenting for severe refractory coronary vasospasm was effective and without serious complications. It can be an alternative and viable option for some patients who are refractory to medical therapy and at a high risk of acute coronary syndrome recurrence.

(c) 2013 S. Karger AG, Basel

\section{Introduction}

Variant angina is caused by spontaneous coronary artery spasm. The coronary arteries in variant angina generally demonstrate organic stenosis, although they may also be angiographically normal. Emotional stress, heavy smok- 
ing, drug addiction, and in vivo inflammatory response can lead to coronary artery spasm $[1,2]$. The release of inflammatory mediators during allergic or hypersensitive and anaphylactic or anaphylactoid insults has been implicated in inducing coronary artery spasm [3]. Although calcium channel antagonists and nitrates are effective for the treatment of variant angina in most patients, $5-30 \%$ of patients are refractory to aggressive medical treatment $[1,4]$. They may have episodes of recurrent chest pain together with complete atrioventricular block, ventricular tachycardia, ventricular fibrillation, acute myocardial infarction, or even sudden death. Although there are individual studies reporting the use of percutaneous transluminal coronary angioplasty (PTCA) and stenting for the treatment of variant angina [5-9], it is not well established or fully discussed in the literature. In the present study, we observed the clinical efficacy of coronary stenting in 21 patients with variant angina refractory to medical treatment.

\section{Subjects and Methods}

\section{Subjects}

Eighty-one (81) patients ( 42 male and 39 female, mean age 52.4 \pm 9.1 years, range $45-78$ ) with a diagnosis of variant angina admitted to the Department of Cardiology of our hospital between January 2003 and June 2011 were included in the study. Typical symptoms included chest pain at rest or sleep, relieved immediately with administration of sublingual nitroglycerin. ST segment elevation on electrocardiograms (ECGs) was greater than $0.1 \mathrm{mV}$ during the onset of chest pain and disappeared when the pain was resolved. Follow-up troponin I and creatine kinase isoenzyme test showed no significant evidence of myocardial necrosis. Patients with acute myocarditis, acute pericarditis, acute myocardial infarction, ventricular aneurysm, dilated cardiomyopathy, early repolarization syndrome, acute pulmonary embolism, and brain-heart syndrome were excluded. Of the 81 patients with variant angina, 21 patients (13 male and 8 female, mean age $54.5 \pm 8.2$ years, range $46-75$ ) were refractory to medical treatment.

\section{Methods}

Medical treatment included calcium channel antagonists (diltiazem hydrochloride tablets at a dose of $90-240 \mathrm{mg} /$ day or nifedipine tablets $30-60 \mathrm{mg} /$ day), nitrates (isosorbide mononitrate tablets at a dose of $40-120 \mathrm{mg} /$ day), lipid-regulating agents (pravastatin sodium at a dose of $20-40 \mathrm{mg} /$ day or atorvastatin calcium 20-40 mg/day), and antiplatelet drugs (aspirin enteric-coated tablets at a dose of $100 \mathrm{mg} /$ day).

Multi-position coronary angiography (CAG) imaging was performed in 81 patients using the GE INNOVA 2100 DSA. Intravascular ultrasound (IVUS) was performed in all 81 patients using a US imaging system (Jomed Co., USA). The catheter was inserted into the distal segment of the coronary artery and slowly removed at a rate of $2 \mathrm{~mm} / \mathrm{s}$. Parameters measured included maximal and minimal cross-sectional area of vessels, maximal and minimal lumen diameter, plaque area, and characteristics of the plaque.
Because coronary artery spasm was not observed using IVUS in 11 of the 21 patients refractory to medical treatment, acetylcholine (Ach) provocative test was done to provoke fatal coronary spasm. Ach was injected into the left coronary artery in 3 patients and into the right coronary artery in 8 patients at a dose of $0.02-0.1$ mg within $15 \mathrm{~s}$, and its effect on the artery was observed for $3 \mathrm{~min}$. In this test, coronary artery spasm was defined as 'transient, total, or sub-total occlusion ( $>90 \%$ stenosis) of a coronary artery with signs/symptoms of myocardial ischemia (anginal pain and ischemic ST changes)' [10]. If the spasm was not relieved within 3 min, nitroglycerin $(0.2 \mathrm{mg})$ was injected into the coronary artery until the spasm was relieved.

Using a guiding catheter, stent implantation was performed after placing a guidewire into the distal end of the coronary segment where the spasm was observed. The drug-eluting stents placed were $2.5-4.5 \mathrm{~mm}$ in diameter and $16-36 \mathrm{~mm}$ in length. The balloon inflation pressure was $12-16$ atm. Placement CAG showed that the stents were well deployed without significant residual stenosis. Dual antiplatelet therapy was indicated for at least 1 year after stent implantation.

Synchronous 12-lead ECG (Nihon Kohden) was performed in the 21 patients refractory to medical treatment when chest pain occurred or abated. The heart rhythm, heart rate, leads with ST elevation, and dynamic changes were recorded.

The name, age, gender, address, and telephone number of the 21 patients who underwent stent implantation were recorded. Telephone follow-up was obtained in all 21 patients at 1,3 , and 6 months and 1 year after stent placement. They were advised to undergo CAG after 9-12 months. Annual follow-up was carried out yearly after the first year up to 8 years.

\section{Results}

Of the 81 patient included in the study, CAG revealed no significant stenosis in $13(16.0 \%)$ patients and $20-75 \%$ fixed stenosis in the other $68(84.0 \%)$ patients (fig. 1a). Fifteen patients had triple-vessel lesions, 20 double-vessel lesions, and 33 single-vessel lesions. The IVUS examination confirmed that the plaques were stable, fibrous, noncalcified, and some eccentric. The IVUS also demonstrated slight enhancement. Intimal hyperplasia at both ends of the lesion was not obvious. When the IVUS probe was placed through the lesion, CAG showed severe coronary artery spasm in 25 patients, 10 of whom were refractory to medical treatment (fig. 1b). The patients felt chest pain at the same time. ST segment elevation was documented on ECG. The symptoms were alleviated by intracoronary injection of nitroglycerin. The 11 patients who underwent Ach provocative test developed episodes of chest pain. CAG showed corresponding segmental vascular spasm in 10 patients and diffuse vascular spasm in 1 patient. ST segment elevation was present on ECG in 11 patients.

The 21 patients refractory to medical treatment presented with recurrent variant angina. ECG revealed ST 


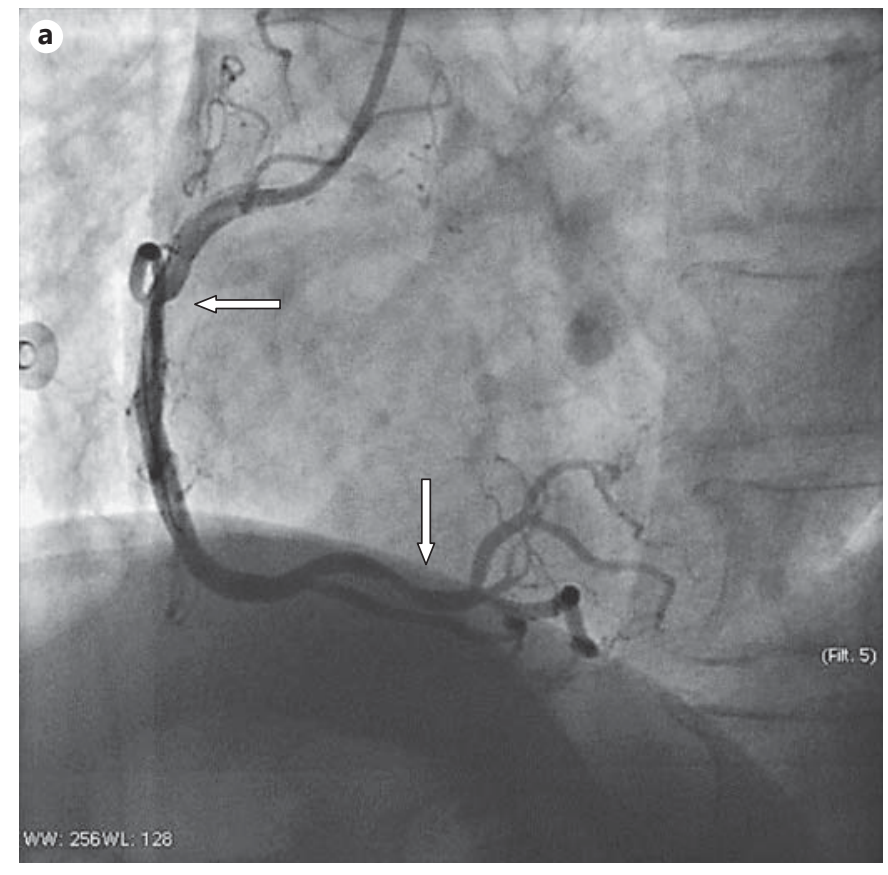

Fig. 1. CAG imaging of a patient with variant angina. a Forty percent stenosis in the middle segment and $60 \%$ stenosis in the distal segment of the right coronary artery. Arrows indicate lesions. b The area of spasm is located in the proximal segment, middle segment, and distal segment of the right coronary artery. The stenosis was greater than $90 \%$ when the guidewire was placed through the lesion. Arrows indicate coronary spasm. c Two stents were placed in the area of spasm in the proximal segment, middle segment, and distal segment of the right coronary artery. Arrows point to stented segments.

segment elevation $>0.1 \mathrm{mV}$ in leads II, III, avF and (or) $\mathrm{V}_{7-9}$, and (or) $\mathrm{V}_{3 \mathrm{R}-5 \mathrm{R}}$ in 16 patients, of whom 2 had ventricular fibrillation and 8 had complete atrioventricular block at the same time. ST segment elevation in leads $\mathrm{V}_{1-4}$ and (or) $\mathrm{V}_{5-6}$, and (or) I, avL was $>0.2 \mathrm{mV}$ in the other 5 patients, of whom 1 had ventricular fibrillation and 1 ventricular tachycardia simultaneously. ECG, CAG,
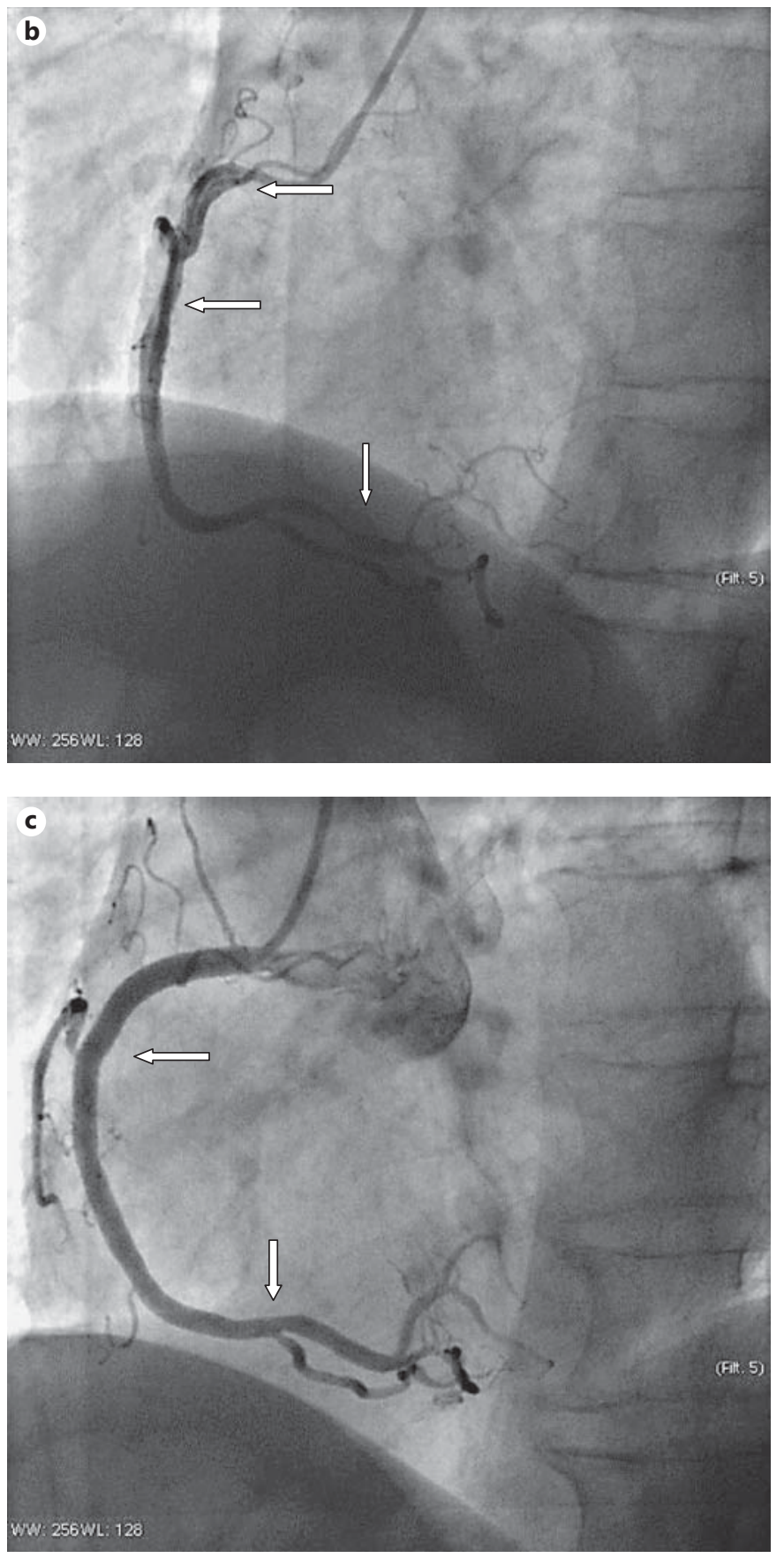

IVUS, and Ach provocative test demonstrated that the spasm site was located in the right coronary artery in 16 patients and in the left anterior descending artery in 5 patients. The right coronary artery spasm site was located in the proximal segment in 4 patients, in the middle segment in 9 patients, in the distal segment in 2 patients, and in the diffuse segment in 1 patient, causing $0-75 \%$ stenosis. The 
left anterior descending artery spasm site was located in the proximal segment in 2 patients and middle segment in 3 patients, causing $0-75 \%$ stenosis. The stents $(2.5-4.5$ $\times 16-36 \mathrm{~mm}$ ) were successfully placed over the full length of the lesions in all 21 patients (fig. 1c), of whom 7 developed recurrent spasms as the stents were advanced through the stenotic segment.

During the 1- to 8-year follow-up period, 1 patient developed recurrent episodes of variant angina. CAG review showed no in-stent restenosis. Severe coronary spasm occurred in the proximal and distal segment adjacent to the stents. Coronary stenting was performed to relieve the chest pain. Five patients had occasional chest pain, but the intensity and duration of the pain symptoms were significantly reduced. Fifteen patients were asymptomatic. CAG at 9-12 months after treatment showed that 3 patients were stenosis free, $20-40 \%$ instent mild intimal hyperplasia was observed in 15 patients, and $50-80 \%$ in-stent restenosis in 3 patients. Coronary stenting was preformed again in 1 patient due to severe restenosis.

\section{Discussion}

The finding of $25.9 \%$ patients who were refractory to pharmacologic treatment and who suffered recurrent variant angina attacks in this study is within the range of $5-30 \%$ reported previously $[1,4]$.

Effective treatment of these patients included the use of corticosteroids, particularly if the patient had an allergic tendency, such as bronchial asthma or chronic thyroiditis [11]. In this study, because the patients with refractory vasospasm did not clearly have an allergic tendency, corticosteroids were not the treatment of choice. Although pacemakers and implantable cardioverter defibrillators are often recommended in some of the patients at high risk of malignant arrhythmias [12], no patient was implanted with such devises in this study because the devices are very expensive. Equally, coronary artery bypass grafting was not used due to surgical trauma, the risk of complications, and poor efficacy [6]. While coronary stenting for variant angina had been used with unsatisfactory outcomes [4-9, 13-14], the use of coronary stenting in this study was very encouraging: the clinical symptoms were completely or significantly relieved in the majority of patients. Only 1 patient $(1 / 21)$ developed recurrent episodes of variant angina and 3 patients $(3 / 21)$ developed significant in-stent restenosis. Compared with previous studies $[4,5,7,9]$, the clinical outcome of our consecutive series appeared to be much better, mostly due to the correct identification of the spasm sites before coronary stenting. Recurrent vasospasm accompanied with chest pain and similar ischemic manifestations were identified on ECG during IVUS examination in 10 patients, during provocative Ach test in the remaining 11 patients, or when balloon and stent were passed through the affected vessel segment in $7 \mathrm{pa}-$ tients. These findings confirmed the original spasm site. However, in the other studies [4, 5, 7-9], the spasm sites were identified based on ECG and CAG or Ach provocative test, which can not only provoke spasm at the site of significant lesions, but also demonstrate stenosis in vessels without significant lesions. This led to a reduced accuracy of judgment, and hence the efficacy of coronary stenting was relatively poor. Percutaneous coronary intervention is not the preferred treatment for diffuse coronary artery spasm $[4,10]$. Similar results were obtained in the present study. One patient with diffuse spasm of the right coronary artery developed recurrent chest pain after stent placement. Follow-up CAG demonstrated severe coronary spasm just proximal and distal to the stents. But it should be noted that drug-eluting stents can induce diffuse coronary spasm after implantation in a few cases. The etiology may be a response to the released medications from the stents or delayed endothelialization after stent placement, leading to abnormal vasoconstriction and vasomotion [15]. Two more stents were then placed. All symptoms were resolved after the second stenting. Percutaneous coronary intervention for diffuse vasospasm should be performed only when there is no better treatment option. Patients who underwent multiple stent placements are at high risk of in-stent thrombosis or restenosis.

Although all of the stents were successfully placed in our series, it should be noted that the risk of vasospasm during stenting is high. Intracoronary injection of nitroglycerin or verapamil is very useful in avoiding acute myocardial infarction. Compared to the patients who gradually stopped taking calcium channel antagonists and nitrates after stent implantation in another study [9], our 21 patients continued medical treatment, knowing that it is effective in reducing the frequency and severity of angina.

The limitations of this study include the small number of patients, short follow-up period, and the retrospective nature and its inherent selection bias. The criteria for deciding who would undergo pharmacologic treatment or coronary stenting was not standardized, and the decision was left to the discretion of the operator. 


\section{Conclusion}

The present study showed that coronary stenting for severe refractory coronary vasospasm was effective and without serious complications. It can be an alternative and viable option for some patients who are refractory to medical therapy and at a high risk of acute coronary syndrome recurrence. Further randomized controlled trials with a large population are needed to compare pharmacologic treatment and coronary stenting in these clinical settings.

\section{References}

1 Kusama Y, Kodani E, Nakagomi A, et al: Variant angina and coronary artery spasm: the clinical spectrum, pathophysiology, and management. J Nihon Med Sch 2011;78:4-12.

-2 Ismail M, Asaad N, Al-Suwaidi J: Adenosineinduced coronary artery spasm: a case report. Med Princ Pract 2012;21:82-85.

-3 Kounis NG: Kounis syndrome (allergic angina and allergic myocardial infarction): a natural paradigm? Int J Cardiol 2006;110:7-14.

4 Yasue H, Nakagawa H, Itoh T, et al: Coronary artery spasm - clinical features, diagnosis, pathogenesis, and treatment. J Cardiol 2008; 51:2-17.

5 Martí V, Ligero C, García J, et al: Stent implantation in variant angina refractory to medical treatment. Clin Cardiol 2006;29:530 533.

6 Khitri A, Jayasuriya S, Habibzadeh MR, et al: Coronary stenting in patients with medically resistant vasospasm. Rev Cardiovasc Med 2010;11:264-270.

$>7$ Sosnowski C, Dabrowski R, Wiernikowski A, et al: Coronary artery stent placement as a treatment of acute coronary syndrome in course of variant angina. Int J Cardiol 2006; 108:259-261.
8 Figueras J, Domingo E, Ferreira I, et al: Persistent angina pectoris, cardiac mortality and myocardial infarction during a 12 year followup in 273 variant angina patients without significant fixed coronary stenosis. Am J Cardiol 2012;110:1249-1255.

-9 Gaspardone A, Tomai F, Versaci F, et al: Coronary artery stent placement in patients with variant angina refractory to medical treatment. Am J Cardiol 1999;84:96-98.

10 JCS Joint Working Group: Guidelines for diagnosis and treatment of patients with vasospastic angina (coronary spastic angina) (JCS 2008). Circ J 2010;74:1745-1762.

11 Takagi S, Goto Y, Hirose E, et al: Successful treatment of refractory vasospastic angina with corticosteroids: coronary arterial hyperactivity caused by local inflammation? Circ J 2004;68:17-22.
12 Epstein AE, DiMarco JP, Ellenbogen KA, et al: ACC/AHA/HRS 2008 guidelines for devicebased therapy of cardiac rhythm abnormalities: a report of the American College of Cardiology/American Heart Association task force on practice guidelines (Writing Committee to revise the ACC/AHA/NASPE 2002 guideline update for implantation of cardiac pacemakers and antiarrhythmia devices) developed in collaboration with the American Association for Thoracic Surgery and Society of Thoracic Surgeons. Circulation 2008;117: 350-408.

13 Cheng TO: Percutaneous coronary intervention for variant angina: balloon vs stent. Catheter Cardiovasc Interv 2002;56:21.

14 Sueda S, Suzuki J, Watanabe K, et al: Comparative results of coronary intervention in patients with variant angina versus those with non-variant angina. Jpn Heart J 2001;42:657667.

15 Brott BC, Anayiotos AS, Chapman GD, et al: Severe, diffuse coronary artery spasm after drug-eluting stent placement. J Invasive Cardiol 2006;18:584-592.
The Efficacy of Coronary Stenting in Patients with Variant Angina 